\title{
Innovando en el empleo inclusivo: proyecto de transición de empresas de inserción al mercado ordinario
}

\author{
Natxo Martínez-Rueda
}

Departamento de Pedagogía Social y Diversidad, Universidad de Deusto

natxo.martinez@deusto.es

\section{Garazi Yurrebaso Atutxa}

Departamento de Pedagogía Social y Diversidad, Universidad de Deusto garaziyurrebaso@deusto.es

\section{Igone Aróstegui Barandica}

Departamento de Didáctica y Organización Escolar, Universidad del País Vasco/Euskal Herriko Unibertsitatea (UPV/EHU)

igone.arostegui@ehu.eus

\section{Joana Revilla Gutiérrez}

Gizarteratzeko eta Laneratzeko Euskadiko Enpresen Elkartea/Asociación de Empresas de Inserción del País Vasco

joana@gizatea.net

\section{Leire Álvarez de Eulate Bada}

Gizarteratzeko eta Laneratzeko Euskadiko Enpresen Elkartea/Asociación de Empresas de Inserción del País Vasco

leire@gizatea.net

Artikulu honen helburua, Europako Gizarte Funtsaren Gizarte Inklusio eta Gizarte Ekonomia Programa Operatiboaren (POISES) barnean eta Bizkaiko Foru Aldundia eta Gipuzkoako Foru Aldundiaren finantzazioaren bitartez, ikerketaekintza metodologia duen proiektu baten esparruan martxan jartzen ari den enplegu arruntari laguntzeko programa baten diseinua aurkeztea da. Gizarteratzeko eta Laneratzeko Enpresetatik enplegu arruntera egiten diren trantsizio-prozesuak hobetzea xede izanda, Gizarteratzeko eta Laneratzeko Enpresetako ibilbidea bukatu eta enplegagarritasun baxuko egoeran dauden pertsonak enplegu arruntean parte-hartzea ahalbidetzen duten faktoreen identifikazioa helburu duen proiektu pilotu bat garatzen ari da. Horretarako, Enplegu Arruntari Laguntzeko Programa (EALP) diseinatu da, 24 pertsonari sostengua emateko erabiltzen ari dena. Artikulu honetan programaren erreferentzia-markoa, elaborazio-prozesua eta programa osatzen duten fase eta erramintak aurkezten dira.

\section{GAKO-HITZAK:}

Laneratzeko enpresak, programa, enplegu arrunta, trantsizioa.
El objetivo de este artículo es presentar el diseño de un programa de apoyo al empleo ordinario que se está implementando en el marco de un proyecto de investigación-acción dentro del Programa Operativo Inclusión Social y Economía Social (POISES) del Fondo Social Europeo y cofinanciado por la Diputación Foral de Bizkaia y la Diputación Foral de Gipuzkoa. Con la finalidad de mejorar los procesos de transición desde las empresas de inserción al mercado ordinario, se está desarrollando un proyecto piloto que persigue identificar los factores que contribuyen a la incorporación al empleo ordinario de personas en situación de baja empleabilidad que han finalizado su itinerario en las empresas de inserción. Para ello, se ha diseñado un programa de apoyo al empleo ordinario (PAEO) que se está utilizando en el apoyo a veinticuatro personas. En este artículo se presenta el marco de referencia del programa y su proceso de elaboración, así como las fases y herramientas que lo componen.

\section{Palabras Clave:}

Empresas de inserción, empleo ordinario, programa, transición. 


\section{Introducción}

Las empresas de inserción se dirigen a promover la empleabilidad de personas con necesidades complejas de inserción laboral a través de mejorar la cualificación profesional, la experiencia profesional y de prestar apoyos para la gestión de las dificultades de la vida de forma que las personas puedan conseguir un empleo permanente y de calidad en las empresas ordinarias (Martínez-Rueda, Galarreta y Aróstegui, 2018). Diversas fuentes (Álvarez De Eulate, 2017; Askunze, 2016; Lázaro y Martínez Polo, 2013; Gallastegi y Martínez, 2011) han identificado la fase de salida de la empresa de inserción y de incorporación al mercado ordinario como una fase crítica en el itinerario de las personas que precisan de un apoyo específico (Bloom, 2010; SIIS Centro de Documentación y Estudios, 2011).

Este acompañamiento personalizado en la transición de la empresa de inserción al empleo ordinario con el objetivo de que mantengan dicho empleo es una necesidad hasta ahora no atendida desde las empresas de inserción, puesto que el trabajo con las personas finaliza una vez que salen de la empresa. Este acompañamiento, que podríamos denominar «apoyo al empleo», es una necesidad detectada en el marco del grupo de acompañamiento a la inserción de Gizatea-Asociación de Empresas de Inserción del País Vasco. El personal técnico de acompañamiento encuentra que para algunas personas que finalizan su itinerario, lo más complicado no es encontrar un empleo en el mercado ordinario, sino mantenerlo. En ese sentido, ya en 2011, en el marco del Seminario para el Desarrollo de las Competencias Relacionales de las y los Profesionales de Acompañamiento, organizado por Gizatea, se apuntaban algunas propuestas para facilitar la transición al empleo ordinario, entre las que destacaba la creación de conexiones entre las empresas de inserción y las empresas «ordinarias», a través por ejemplo de programas como el «empleo con apoyo» (Gallastegi y Martínez, 2011).

A pesar de las altas tasas de incorporación al mercado ordinario -el 69\% en 2017- (Gizatea, 2018), sigue existiendo un porcentaje variable de personas que, o bien no consiguen acceder a un empleo en el mercado abierto o bien no consiguen mantenerlo. En este sentido, se corre el riesgo de que en esos casos el esfuerzo desarrollado por las personas y por las empresas no obtenga los resultados esperados. Por ello, y tomando como referencia otros programas que han demostrado su eficacia (Frederick y Vanderweele, 2019; Modini et al., 2016; Dowler y Walls, 2014) se plantea que, si las personas con mayores dificultades de inserción laboral que salen de las empresas de inserción cuentan con un apoyo cualificado en el acceso y mantenimiento del empleo, mejorarán sus resultados.

Para responder a esta necesidad, Gizatea está desarrollando un proyecto -en el marco del
Programa Operativo Inclusión Social y Economía Social (POISES) del Fondo Social Europeo y cofinanciado por la Diputación Foral de Bizkaia y la Diputación Foral de Gipuzkoa- con la finalidad de promover la inclusión social fomentando mercados laborales inclusivos y desarrollando estrategias de intervención integral, a través, por un lado, de la sensibilización del sector empresarial en materia de empleo inclusivo y del asesoramiento a empresas de la economía social y/o mercantiles para la contratación de personas en situación o riesgo de exclusión y, por otro, del diseño, pilotaje y evaluación de un modelo de apoyo al empleo para personas en situación o riesgo de exclusión que, dando continuación al itinerario personalizado en la empresa de inserción, mejore la calidad de la transición del empleo protegido al empleo ordinario y contribuya al mantenimiento de dicho empleo.

En este sentido, el objetivo del proyecto se define como “diseñar, pilotar y evaluar un modelo de apoyo a la incorporación y mantenimiento del empleo para personas en situación o riesgo de exclusión", que, dando continuación al itinerario personalizado en la empresa de inserción, mejore la calidad de la transición del empleo protegido al empleo ordinario y contribuya al mantenimiento de dicho empleo.

Para la consecución de este objetivo se realizarán acciones de:

- Prospección y asesoramiento empresarial para la contratación de personas en situación o riesgo de exclusión que finalizan sus itinerarios en empresas de inserción y que presentan especiales dificultades para el acceso y mantenimiento del empleo ordinario.

- Diseño colaborativo de una metodología de “apoyo al empleo" para personas en situación o riesgo de exclusión social.

- Pilotaje y evaluación de dicha metodología con veinticuatro personas en situación o riesgo de exclusión que finalicen sus itinerarios en 2018 y 2019. Con estas personas se realizará un acompañamiento personalizado de doce meses de duración durante su primer año de trabajo en una empresa "ordinaria".

- Difusión de los resultados del proyecto e incorporación de los aprendizajes a la metodología de las empresas de inserción.

Una primera fase de este proyecto ha consistido en el diseño de la metodología de apoyo al empleo desde las empresas de inserción, que se describe a continuación.

\section{Marco de referencia para el diseño de un programa de apoyo al empleo}

A continuación se señalan las principales referencias que sirven de punto de partida a la propuesta: la 
finalidad del programa en el marco de las empresas de inserción, la empleabilidad como un concepto interactivo y dinámico, el acompañamiento como modelo de intervención y la prestación de apoyos como eje del proceso de acompañamiento.

\subsection{Incorporación al mercado ordinario: finalidad de las empresas de inserción}

El momento de salida de la empresa de inserción e incorporación al mercado ordinario de trabajo se ha considerado habitualmente el momento crítico por cuanto es el momento en que se verifica si el proceso de formación-acompañamiento-empleo consigue los resultados de inserción. Es también el momento en el que emergen las diversas contradicciones y limitaciones relacionadas con la situación actual del mercado de trabajo (precariedad, bajos salarios, etc.) y el papel de intermediación que juegan las empresas de inserción. En este sentido, es relevante tener presentes estas contradicciones ya que van a aparecer en el proceso y va a ser necesario gestionarlas.

En este marco, partimos de dos premisas complementarias que van a orientar la propuesta que realizamos y que se refieren a la necesidad de un trabajo simultáneo con las personas y con el entorno empresarial. En este sentido, hay que destacar la importancia crítica que tiene la relación con las empresas para crear un contexto que permita la inserción de las personas que salen de la empresa de inserción. Para ello, será necesario dar pasos en la dirección de establecer-profundizar alianzas con empresas y, en general, desarrollar diferentes acciones de intermediación y colaboración con el mayor número de empresas.

Por otra parte, en este trabajo partimos de la necesidad de reforzar el soporte que se da a las personas trabajadoras en inserción en el momento de salida, sobre todo en aquellas situaciones en las que precisan apoyos para lograr y mantener un puesto de trabajo. Para ello, es importante desarrollar modelos de soporte y seguimiento laboral de más intensidad o procesos de apoyo en el mismo puesto de trabajo (trasladando algunos elementos del llamado "empleo con apoyo").

\subsection{La empleabilidad, una cuestión de dos}

El término empleabilidad tiene una larga tradición con múltiples sentidos y usos (Serrano, 2000). Para algunos se ha convertido en un concepto confuso (De Grip, Loo y Sanders, 2004) al haber ido incorporando de forma progresiva nuevos elementos y componentes, coexistiendo diferentes definiciones (Williams, Dodd, Steele y Randall, 2015). Esta diversidad conceptual está relacionada también con las diferentes comprensiones del problema del desempleo y de las propias personas desempleadas. Hay que resaltar que una buena parte de esos enfoques -y muchas prácticas de inserción laboral incluso las propias empresas de inserción (Llinares, Córdoba y Zacarés, 2012; Martínez Morales, Bernad y Navas, 2012) - se han centrado en los factores relativos a la mano de obra, individualizando el problema y situando la responsabilidad del desempleo en las personas - como falta o carenciay no tanto en el contexto como riesgo social.

La visión actual de empleabilidad implica una visión amplia y dinámica y debe abarcar factores tanto individuales como contextuales (De Grip et al., 2004; Llinares, Zacarés y Córdoba, 2016; McQuaid y Lindsay, 2005), en una conceptualización cada vez más compleja y multidimensional (Forrier y Sels, 2003; Williams et al., 2015). Estos planteamientos son convergentes con la literatura orientada a la identificación de barreras al empleo (Blumenberg, 2002), que integra la diversidad de obstáculos que tienen que afrontar las personas con especiales dificultades de encontrar un empleo.

En este sentido resulta necesario adoptar un concepto de empleabilidad amplio -recogiendo el mayor número de elementos-, dinámico -incorporando los cambios que se producen en el tiempo-e interactivo - enfatizando la relación entre los diferentes elementos-. En consecuencia, formulamos la siguiente definición de empleabilidad:

El conjunto de factores y condiciones tanto individuales como contextuales $-y$ la relación entre ellos- que influyen en que una persona puede conseguir un empleo, mantenerlo y mejorarlo (Martínez-Rueda, Galarreta y Arostegui, 2018: 130).

En esta definición se busca mantener el equilibrio entre la responsabilidad personal y social, así como el alcance individual y colectivo, e incluye en consecuencia el acompañamiento a las personas y el acompañamiento a las empresas (Programa Incorpora de La Caixa e Instituto Universitario Avedis Donabedian, 2016).

\subsection{El acompañamiento como modelo de actuación profesional}

El acompañamiento se entiende como una metodología de intervención profesional (Fantova, 2009; Pérez Eransus, 2004; Planella, 2008) de carácter relacional, educativa, procesual, centrada en la persona, basada en fortalezas, orientada a la acción y mediadora en el acceso a recursos. Es un modelo de intervención que ha sido adoptado por las empresas de inserción (Fernández, Galarreta y Martínez, 2007; Faedei y Aeress, 2014; MartínezRueda, Galarreta Lasa y Aróstegui Barandica, 2018) como referencia para la actuación profesional y el desarrollo de itinerarios de inserción sociolaboral.

En esta línea, el acompañamiento (Gallastegi y Martínez, 2011) se entiende como una forma de 
actuación profesional que parte del respeto a la persona para crear una relación de cercanía y confianza que permita establecer acuerdos y pactos, con una orientación a la acción. Ello supone aprendizaje y cambio por parte de todas las personas implicadas, en el marco de un proceso itinerario-, utilizando diferentes apoyos naturales y profesionales - prestaciones-.

Esto implica tomar como punto de partida de las actuaciones profesionales el punto de vista de la propia persona. Se dice, en este sentido, que las personas son las que marcan sus metas - aquellos logros o resultados importantes para ellas $-y$ lo que desean, y que nuestra función es acompañar desde el conocimiento profesional disponible. Se suele apuntar también la necesidad de ver desde lo positivo a las personas y no tanto desde las carencias, confiando en la capacidad de la persona y manteniendo siempre altas expectativas.

Una primera implicación de este enfoque es la necesidad de una gran flexibilidad o versatilidad en el comportamiento de los y las profesionales y de los servicios y soportes que se prestan a las personas. La pregunta central se formularía en términos de qué es importante para la persona. Centrarse en los logros lleva a trabajar conjuntamente a persona y profesional desde un esquema de colaboración. Implica, asimismo, una atención especial a los procesos de relación y comunicación, tratando de identificar de una manera permanente las prioridades de las personas.

Este enfoque conlleva la necesidad de dedicar tiempo, de revisar constantemente con las personas, de hablar, de analizar, de dialogar, de comentar, de preguntar, de reunirse... de seguir el proceso de las personas y de los grupos de trabajo que se van formando, de estar ahí cuando se nos precisa; en definitiva, de acompañar.

Algunas de las claves de éxito en el acompañamiento son las siguientes:

- Respeto y consideración de la persona como agente principal de su propia vida.

- Mantener, en consecuencia, altas expectativas en las cosas que pueden llegar a hacer si cuentan con los apoyos necesarios.

- La confianza es la base de la relación, que se promueve a través del interés genuino por el bienestar de la persona, la validación de su punto de vista y el cumplimiento de los compromisos.

- Los acuerdos orientados a la acción son un motor potente de transformación ya que movilizan las capacidades de las personas. Hacer peticiones con claridad, haciéndonos cargo de la situación y desde el respeto a la persona, facilita los acuerdos.

- El uso de los apoyos naturales y profesionales es la garantía del éxito en esas acciones.
- Elaborar esas experiencias de éxito o reconocer los esfuerzos y ayudar a entender lo que ha ocurrido contribuye a que las personas puedan ir desarrollando narraciones alternativas sobre sí mismas, sus vidas y el contexto en el que se producen.

En síntesis, establecer una relación de colaboración, de hacer cosas conjuntamente para conseguir determinadas metas, es el proceso básico desde el que se puede desplegar el conjunto de apoyos que prestamos. En consecuencia, es muy importante generar confianza, el ingrediente básico para una relación de colaboración. El respeto es otro ingrediente y supone la aceptación del otro, el reconocimiento de su legitimidad y autonomía.

Algunas de las cosas que desarrollamos para generar confianza son las siguientes:

- Clarificar expectativas y roles a través de recordar el encuadre como profesional de apoyo y de explicar nuestra función mediante ejemplos de aspectos de su vida en los que podemos prestarle apoyo.

- Promover que la persona experimente el control de la situación a través de pedir permiso, preguntar más que indicar, respetar los espacios sin invadir, respetar decisiones y promover que las personas no hagan cosas que no quieran hacer, agradecer su esfuerzo y lo que aportan, etc.

- Crear múltiples oportunidades de interacción a través de mostrarse disponible, buscar momentos y espacios adecuados, o emplear canales diversos (llamadas de teléfono, WhatsApp, espacios informales, etc.).

- Cumplir impecablemente lo que acordamos.

- Informar, escuchar, empatizar, aceptar cuando no hay demanda, tratando de crearla.

- No juzgar ni cuestionar, validar su forma de ver como legítima dando tiempo a los procesos.

\subsection{El modelo de apoyos, una referencia para el acompañamiento}

El apoyo social que se recibe ha sido identificado como un aspecto clave en los procesos de inserción laboral de personas en situación de desventaja (Nga y Chan, 2015). Por ello, identificar los diferentes apoyos que pueden recibir las personas nos puede ayudar a definir la propuesta metodológica. En esta línea, lo que se ha venido a denominar como "modelo de apoyos" se ha desarrollado a partir de las aportaciones de la Asociación Americana de Discapacidades Intelectuales y del Desarrollo (AAIDD) desde su propuesta de 1992, que se mantiene en las más recientes (AAIDD, 2011). Coincide con toda una corriente de pensamiento que también se refleja en las diferentes clasificaciones de la Organización Mundial de la Salud (OMS, 2001) y que, desde nuestro punto de vista (Martínez-Rueda y 
Fernández, 2007), tienen como elementos centrales los siguientes:

- El eje de actuación profesional no está en las capacidades o competencias de las personas, sino en la participación y el funcionamiento en los diversos entornos vitales, en nuestro caso el entorno laboral.

- El funcionamiento-participación de las personas depende de la accesibilidad de los entornos laborales y de los apoyos que el medio es capaz de organizar.

- El proceso de facilitación del funcionamientoparticipación toma como referencia central a la persona, sus expectativas y aspiraciones.

En síntesis, los apoyos se entienden como recursos y estrategias que facilitan el desempeño exitoso de una persona en los diferentes contextos vitales, promoviendo el logro de metas valiosas. El modelo de apoyos implica una manera diferente a la tradicional de pensar y organizar la respuesta a las necesidades de las personas, partiendo como eje central de la persona, enfatizando la influencia del contexto en el funcionamiento de las personas $y$, por último, diversificando y personalizando los servicios.

Los diferentes componentes del modelo de apoyos tal como propone la AAIDD (2011) y que podemos tomar como referencia son los siguientes:

- Los resultados personales, que son la meta de los servicios, toman como referencia fundamental las aspiraciones de las personas.
- Las áreas de apoyo que incluyen los ámbitos o contextos en los que se pueden prestar los apoyos para el logro de los resultados personales.

- Las funciones de apoyo que establecen el tipo de apoyo que se presta y que se concretan a través de una variedad de actividades y acciones.

- Las fuentes de apoyo que se refieren a quien presta el apoyo: la persona, la red natural o los profesionales.

- La intensidad de los apoyos que se establece a partir de la frecuencia, la duración y los ámbitos o áreas de apoyo implicadas. En base a estas variables se suelen identificar diferentes intensidades. Por ejemplo, la AAIDD diferencia entre apoyo intermitente, limitado, extenso o generalizado. El programa Incorpora propone hablar de nivel básico, intermedio, alto y muy alto (Programa Incorpora de la Caixa e Instituto Universitario Avedis Donabedian, 2016)

Los ámbitos de apoyo se relacionan con las diferentes tareas implicadas en el acceso y mantenimiento de un puesto de trabajo (búsqueda de empleo, procesos de selección, incorporación, mantenimiento y promoción, etc.). Las funciones de apoyo las podemos clasificar atendiendo al esquema de la Tabla 1. Hay que tener en cuenta que no es una propuesta cerrada, sino que tiene un carácter orientativo para identificar el apoyo principal que se le presta a la persona, aunque es probable que se produzcan solapamientos.

Tabla 1. Descripción de las funciones de apoyo al empleo

\begin{tabular}{|c|c|}
\hline Tipo de apoyo & Definición y ejemplos de actividades \\
\hline $\begin{array}{l}\text { Información y } \\
\text { orientación }\end{array}$ & $\begin{array}{l}\text { La actividad de apoyo consiste en aportar información a la persona, en diferentes formatos, que le ayudan a buscar } \\
\text { empleo o mantenerlo (por ejemplo, trasladar posibles ofertas de empleo, informar de cuestiones que tiene que considerar } \\
\text { en un proceso de selección, etc.). También consiste en ayudar a la persona a evaluar una situación y a elaborar un plan, } \\
\text { incluyendo plantearse metas y proponer acciones para conseguirlo. Por ejemplo, ayudar a la persona a planificar la } \\
\text { búsqueda de empleo, hacer un listado de posibles empleos y prever algunos problemas que puedan surgir. }\end{array}$ \\
\hline Formación & $\begin{array}{l}\text { Es un tipo de ayuda ocasional que consiste en una actividad específica que se desarrolla durante un tiempo concreto, } \\
\text { dirigida a que la persona incorpore una habilidad concreta, tal como solicitar una cita por Internet, preparar una entrevista } \\
\text { o defender de forma correcta sus derechos, etc. }\end{array}$ \\
\hline Supervisión & $\begin{array}{l}\text { Este tipo de apoyo consiste en acompañar a la persona, asegurándose que se desempeña adecuadamente (por ejemplo, } \\
\text { estar presente en una llamada telefónica, supervisar cómo se desempeña en determinadas tareas, etc.). La persona puede } \\
\text { requerir algún tipo de indicación frente a algún imprevisto, pero en su conjunto se desempeña con autonomía. }\end{array}$ \\
\hline $\begin{array}{l}\text { Ayudas } \\
\text { técnicas y } \\
\text { productos de } \\
\text { apoyo }\end{array}$ & $\begin{array}{l}\text { Se trata no solo de apoyar una actividad previa sino también de dar apoyo a la realización de la misma actividad a través } \\
\text { de algunas ayudas técnicas, por ejemplo, con un cartel que indica los pasos de una tarea o con una app que le avisa de las } \\
\text { tareas a realizar cada día. }\end{array}$ \\
\hline Asistencia & $\begin{array}{l}\text { Esta actividad de apoyo consiste en prestar apoyo físico (ayudarle físicamente a realizar alguna actividad), o una ayuda } \\
\text { gestual o verbal (instrucciones) para asegurar que la persona pueda realizar una determinada actividad. También puede } \\
\text { incluir aquellas actividades en la que se "sustituye" a la persona en la realización de alguna actividad (por ejemplo, Ilamar } \\
\text { por teléfono en el caso de una persona con una limitación auditiva importante). }\end{array}$ \\
\hline $\begin{array}{l}\text { Apoyo } \\
\text { psicosocial }\end{array}$ & $\begin{array}{l}\text { Es un apoyo específico orientado a activar a la persona y tiene que ver con los sentimientos de valía personal, gestión } \\
\text { de conflictos, motivación para hacer cosas y sentirse comprendido. Se desarrolla a través de conversaciones regulares. } \\
\text { Aunque es un componente de cualquier intervención, este apoyo se produce cuando se ha identificado como un aspecto } \\
\text { que está dificultando el avance de la persona. }\end{array}$ \\
\hline Mediación & $\begin{array}{l}\text { Es una actividad de apoyo que se orienta a la mejora de la interacción entre la persona y el medio laboral, familiar o } \\
\text { comunitario en el que se desenvuelve. Puede incluir actividades de escucha, de proponer acuerdos o de sensibilizar al } \\
\text { medio. }\end{array}$ \\
\hline $\begin{array}{l}\text { Defensa de } \\
\text { derechos y } \\
\text { apoyo jurídico }\end{array}$ & $\begin{array}{l}\text { Aunque algunos aspectos de este tipo de apoyo se pueden incluir en los descritos (información y orientación, formación, } \\
\text { supervisión, etc.), por la especificidad de conocimientos que implica se ha incluido como un tipo de apoyo diferenciado. }\end{array}$ \\
\hline
\end{tabular}




\section{Metodología de elaboración del programa}

Para la elaboración de la propuesta hemos partido del proceso y herramientas que se utilizan en las empresas de inserción (Martínez-Rueda y Galarreta, 2019) dado que es el contexto desde el que se va a desarrollar el proyecto. El proceso de trabajo de cara al diseño del programa ha tenido tres fases bien diferenciadas:

- Fase 1. Revisión de un conjunto de programas y propuestas metodológicas desarrolladas para la transición y el apoyo al empleo ordinario (Tabla 2) que se caracterizan por disponer de desarrollos teórico-prácticos sólidos, que tienen reconocimiento en los ámbitos profesionales y que puedan ser replicados 0 adaptados en otros contextos.
- Fase 2. Contraste y validación de la propuesta metodológica mediante dos grupos de profesionales con experiencia en el desarrollo de procesos de acompañamiento e intermediación con personas con especiales dificultades de inserción laboral. Para ello, se realizan dos entrevistas grupales. La primera entrevista con una duración de cinco horas se realiza a un grupo de cinco profesionales de la Fundación San Martín de Porres (Madrid) que desarrollan un programa de empleo con apoyo con personas en exclusión. La segunda entrevista, de dos horas, se realiza a dos profesionales de Zabaltzen-Sartu, dentro del programa Grupos de Activación Inclusiva (GAl). En la Tabla 3 se presenta un resumen de los obstáculos que se han identificado y las sugerencias metodológicas que se proponen a partir de su experiencia.

Tabla 2. Programas revisados para la elaboración de la propuesta

\begin{tabular}{|c|c|}
\hline Programa & Descripción \\
\hline $\begin{array}{l}\text { Caja de herramientas para la diversidad de la } \\
\text { Unión Europea de Empleo con Apoyo (EUSE, } \\
\text { 2010; Jordán de Urríes, 2005) }\end{array}$ & $\begin{array}{l}\text { Conjunto de herramientas basado en el Modelo de Empleo con Apoyo de personas con } \\
\text { discapacidad y que quiere ser transferido a otros grupos o colectivos en situación de } \\
\text { desventaja. }\end{array}$ \\
\hline $\begin{array}{l}\text { Programa Incorpora de la Caixa e Instituto } \\
\text { Universitario Avedis Donabedian-UAB, 2016) }\end{array}$ & $\begin{array}{l}\text { Programa para promover la inserción laboral que propone un trabajo a tres niveles, a través } \\
\text { de una serie de fases y un conjunto de herramientas, para facilitar la intermediación y } \\
\text { comunicación entre persona-entidades-empresas. }\end{array}$ \\
\hline $\begin{array}{l}\text { Customized Employment (National Center on } \\
\text { Workforce and Disability/Adult, 2005; 2006) }\end{array}$ & $\begin{array}{l}\text { Programa dirigido a personas con discapacidad que comprende un conjunto de acciones } \\
\text { para la consecución de un empleo personalizado, a través de la individualización de la } \\
\text { relación entre la persona que busca empleo y los empleadores, y cuyo resultado sea una } \\
\text { alianza de empleo compartido. }\end{array}$ \\
\hline $\begin{array}{l}\text { Empleo personalizado. Una oportunidad para } \\
\text { crear situaciones únicas. (Plena Inclusión, } \\
\text { 2018) }\end{array}$ & $\begin{array}{l}\text { Conjunto de estrategias y recursos con el que se explora el talento y los recursos que tiene la } \\
\text { persona, y se negocia de manera personalizada con el empleador para encontrar el empleo a } \\
\text { la medida. Basado en el Modelo de Empleo Personalizado (National Center on Workforce and } \\
\text { Disability/Adult, 2006). }\end{array}$ \\
\hline $\begin{array}{l}\text { Guía para la integración laboral de personas } \\
\text { con trastorno mental (Hilarión y Koatz, 2012) }\end{array}$ & $\begin{array}{l}\text { Guía, desarrollada dentro del Programa Incorpora de La Caixa, que comprende diferentes } \\
\text { herramientas con el fin de facilitar el acceso al mundo laboral de este colectivo. }\end{array}$ \\
\hline $\begin{array}{l}\text { Manual de acompañamiento en las Empresas } \\
\text { de Inserción Martínez-Rueda y Galarreta, } \\
\text { 2018) }\end{array}$ & $\begin{array}{l}\text { Manual que recoge y analiza momentos clave y diferentes herramientas de registro para el } \\
\text { desarrollo y seguimiento de los procesos de acompañamiento a la persona trabajadora de } \\
\text { inserción, y de su promoción personal, social y cultural y la búsqueda y apoyo en empleo } \\
\text { ordinario. }\end{array}$ \\
\hline
\end{tabular}

Tabla 3. Grupos de contraste, identificación de obstáculos y sugerencias metodológicas

\begin{tabular}{|c|c|}
\hline Dificultades/obstáculos en el proceso & Sugerencias metodológicas \\
\hline $\begin{array}{l}\text { - Dificultades en el mantenimiento del empleo y del } \\
\text { puesto (ritmo, adaptación, motivación). } \\
\text { - Dificultades relacionadas con el apoyo emocional y } \\
\text { la gestión de la vida no laboral. } \\
\text { - La conciliación vida laboral y familiar. } \\
\text { - El transporte en algunos casos es una dificultad } \\
\text { importante. } \\
\text { - Una parte importante de las empresas no están } \\
\text { dispuestas a mantener relaciones estables de } \\
\text { colaboración. El apoyo tiene que ser más a la } \\
\text { persona. } \\
\text { - Las condiciones que ofrecen algunas empresas lleva } \\
\text { a la necesidad de prestar apoyos jurídicos. } \\
\text { - En algunos casos, hay discriminación por edad, sexo } \\
\text { y origen y las propias condiciones del mercado de } \\
\text { trabajo (temporalidad, precariedad, etc.). } \\
\text { - Hay un salto importante entre el funcionamiento de } \\
\text { la empresa de inserción y la empresa ordinaria. } \\
\text { - Es frecuente que las personas no se atrevan } \\
\text { a expresar lo que realmente quieren o sus } \\
\text { expectativas, y tienden a responder con dosis altas } \\
\text { de deseabilidad. } \\
\text { - Mucha variabilidad de los procesos, en función de } \\
\text { cada persona y cada empresa. }\end{array}$ & $\begin{array}{l}\text { - Es importante que la persona decida la forma y modalidad de acompañamiento. } \\
\text { emocional (psicosocial), funcionando como red de apoyo social con un estilo } \\
\text { de seguimiento frecuente e informal; siendo el tipo de apoyo y su intensidad } \\
\text { consensuado por persona y empresa, y buscando el equilibrio y tensión entre } \\
\text { apoyos-autonomía. } \\
\text { - Las acciones para asegurar el mantenimiento del puesto deben poner el centro en } \\
\text { realizar un análisis del perfil de la persona y del puesto, para identificar de forma } \\
\text { temprana las dificultades y exigencias del puesto como ritmo, relaciones (muchas } \\
\text { veces no explicitadas) y poder gestionarlo con un plan de apoyos ajustado. } \\
\text { - En algunos casos puede ser muy interesante prestar apoyo en la incorporación, } \\
\text { adaptación a la empresa y aprendizaje del puesto. } \\
\text { - Encuentros regulares y frecuentes con las personas y las empresas. } \\
\text { - En el proceso de acompañamiento, contemplar la posibilidad de mantener } \\
\text { acciones formativas o de apoyo (talleres, sesiones de simulación, apoyo mutuo, } \\
\text { tutorías, etc.); o preparación específica procesos de selección. } \\
\text { - La diversidad de empresas y su casuística requiere cada vez más contar con } \\
\text { apoyos jurídicos. } \\
\text { - Con el fin de aumentar posibilidades de encontrar puestos de trabajo afines a } \\
\text { las necesidades y perfil de las personas, es muy importante que se incluya en } \\
\text { el perfil profesional de los profesionales de apoyo un amplio conocimiento del } \\
\text { tejido empresarial del entorno. } \\
\text { - Es importante identificar el nivel de colaboración al que está dispuesta la } \\
\text { empresa para evitar "fracasos", que suelen cerrar procesos posteriores, y con } \\
\text { aquellas con las que se pueda establecer relaciones estables de colaboración. }\end{array}$ \\
\hline
\end{tabular}


- Fase 3. Análisis de la propuesta metodológica y contraste con el equipo de profesionales que van a implementar el programa. Para ello, se organizan dos jornadas de trabajo en las que participan dos profesionales de Gizatea como responsables del proyecto, diecisiete profesionales de las empresas de inserción y sus entidades promotoras (trece personas técnicas de acompañamiento a la inserción y cuatro prospectoras laborales) y tres personas del equipo de investigación responsable del diseño del programa.

El proceso de trabajo se desarrolla en dos jornadas de una duración de cinco horas cada una. En la primera sesión se presenta el Programa de Apoyo al Empleo Ordinario a través de las fases y herramientas propuestas, con el objetivo de analizarlas y recoger sugerencias y propuestas de mejora. La segunda sesión se dirige a la aplicación del programa, haciendo especial hincapié en las herramientas y la planificación del acompañamiento desde las situaciones concretas de las personas participantes. En esta jornada de formación se establece también el procedimiento y herramientas de seguimiento del proyecto piloto.

\section{Programa de apoyo al empleo ordinario}

La referencia que hemos tomado a la hora de ordenar el proceso metodológico es el apoyo que se presta a la persona, aunque también se desarrollen acciones de sensibilización, prospección o intermediación dirigidas a las empresas o a otros agentes.

En este apartado definimos los apoyos que se pueden prestar a las personas atendiendo a las diferentes fases o momentos que implica el conseguir y mantener el empleo. Tal como se recoge en la Tabla 4, las fases que hemos identificado son las habituales en los procesos de inserción laboral.

Tabla 4. Fases del programa

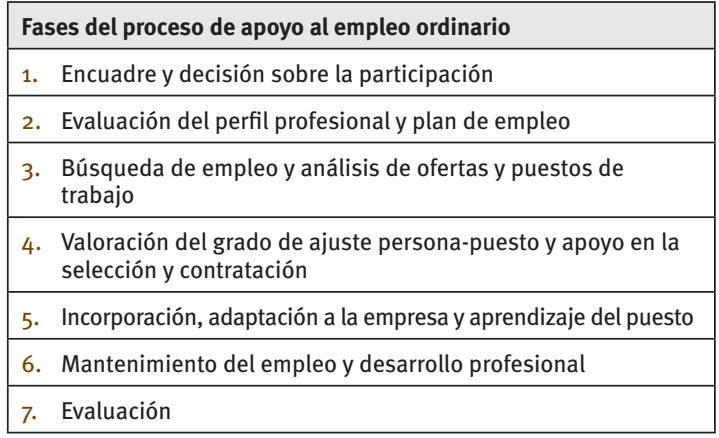

Es importante señalar que estas fases van a desarrollarse en unos tiempos diferentes en cada caso, no siendo posible establecer una temporalización común. Aun así, es importante que en cada caso particular se definan los tiempos previstos en la medida en que eso contribuye a delimitar y acotar tanto las expectativas de los agentes como las acciones a desarrollar.

Aunque no se corresponde con una fase, hay otros aspectos de la vida de la persona que inciden en el proceso de inserción y que, en muchas ocasiones, suponen importantes barreras al acceso o mantenimiento del empleo (Fernández et al., 2016). Estas barreras que tienen que ver con circunstancias personales y sociales (conciliación, salud, ingresos, etc.) condicionan de una manera muy importante las posibilidades de conseguir y mantener el empleo y, en consecuencia, será preciso tenerlas presentes. Esta dimensión del apoyo, que hemos definido como “acompañamiento social” (Martínez et al., 2018) va a tener un carácter transversal que va a cruzar todas las fases que se proponen. A continuación se van a describir cada una de estas fases, atendiendo a su justificación, sentido y objetivos, formas de implementación y herramientas de apoyo.

\subsection{Encuadre y decisión de participación}

La primera fase consiste en informar acerca del funcionamiento del programa a la persona, los compromisos que conlleva y los apoyos disponibles. Es un momento importante porque permite realizar el encuadre del programa que implica la clarificación de expectativas y los compromisos que se asumen. El encuadre es un concepto de uso frecuente en diferentes contextos educativos, psicológicos 0 sociales con sentidos diversos. En el contexto de este programa, se refiere a las condiciones que consideramos necesarias para que se desarrolle adecuadamente el proceso, estableciendo a través de un proceso dialógico un acuerdo o contrato acerca de lo que vamos a hacer y cómo lo vamos a hacer. En base a la información facilitada, la persona toma una decisión informada acerca de su participación o no en el programa. Se considera conveniente fijar el acuerdo en un documento escrito que también salvaguarde la autonomía de la persona y su libre participación en el programa.

El Programa de Apoyo al Empleo se desarrolla en el marco del recorrido de esa persona en la empresa de inserción, lo que puede influir en cómo articular los pasos a desarrollar. Entendemos que se ha construido una relación de confianza y cercanía que nos permite desarrollar el proceso de acompañamiento sobre una base sólida. En cualquier caso, es muy relevante este encuadre inicial (formulación de expectativas, roles y normas de funcionamiento que delimitan tanto los comportamientos posibles como las interacciones entre las personas). Es necesario que este encuadre sea contrastado/negociado a través de un proceso de diálogo. En él es importante definir, presentar (incluyendo documentos en formato accesible) el rol del profesional: qué hacemos, qué no hacemos. En la Tabla 5 se presentan los principales aspectos a tener en cuenta en esta fase y se identifican las herramientas que se utilizarán. 


\begin{tabular}{|c|c|c|c|}
\hline Subfases & Objetivos & Indicaciones estrategias & Herramientas \\
\hline Encuadre & $\begin{array}{l}\text { - Informar a la persona de las } \\
\text { características, condiciones e } \\
\text { implicaciones de su participación en } \\
\text { el programa. } \\
\text { - "Negociar" las expectativas y } \\
\text { condiciones de la participación, tanto } \\
\text { de la persona en inserción como de } \\
\text { las técnicas. } \\
\text { - Generar ilusión y compromiso. }\end{array}$ & $\begin{array}{l}\text { - Dar información en diferentes formatos } \\
\text { sobre el programa. } \\
\text { - Enfatizar el protagonismo y control por } \\
\text { parte de la persona del proceso. } \\
\text { - Dialogar sobre miedos y expectativas, } \\
\text { preferencias o intereses. } \\
\text { - Tener presente que no siempre las } \\
\text { personas se atreven a expresar lo que } \\
\text { realmente desean. } \\
\text { - Mostrar confianza en la persona. }\end{array}$ & $\begin{array}{l}\text { Hoja o folleto } \\
\text { Informativo. }\end{array}$ \\
\hline $\begin{array}{l}\text { Acuerdo de } \\
\text { participación }\end{array}$ & $\begin{array}{l}\text { - Tomar una decisión informada. } \\
\text { - Establecer un primer acuerdo acerca } \\
\text { de cómo se va a funcionar. }\end{array}$ & $\begin{array}{l}\text { - Revisar los compromisos y firmar el } \\
\text { documento. } \\
\text { - Establecer un primer encuentro-tutoría. } \\
\text { - Entregar cuaderno-carpeta personal. }\end{array}$ & $\begin{array}{l}\text { - Documento de } \\
\text { participación y } \\
\text { confidencialidad. } \\
\text { - Carpeta/cuaderno } \\
\text { personal. }\end{array}$ \\
\hline
\end{tabular}

\subsection{Evaluación del perfil profesional y plan de empleo}

Entendiendo el acompañamiento como un proceso personalizado que parte de la valoración de la situación individual de la persona, la finalidad de esta segunda fase es realizar una evaluación inicial que permita revisar o actualizar el perfil profesional de la persona y, en consecuencia, elaborar un plan de empleo que incorpore los objetivos y apoyos más ajustados a su realidad.

El proceso de valoración o evaluación se entiende como un proceso individualizado (Incorpora, 2016) y centrado en la persona (EUSE, 2010) que parte, como se recoge en el apartado anterior, desde la propia aceptación de la participación en el programa. Esta aceptación de participación involucra a la persona en la toma de decisiones sobre su futuro profesional $y$, por consiguiente, en el diseño del plan de empleo. Para ello, se adopta la idea de que es la responsable principal de dirigir y decidir sobre su propio proceso, desde un enfoque de capacitación o empoderamiento (EUSE, 2010), ya que la experiencia ha demostrado la estrecha relación que existe entre el compromiso e involucración plena de la persona en su plan y el ajuste laboral y resultados de empleo satisfactorios (EUSE, 2010).

En este momento, a su vez, cobra especial relevancia la consideración inicial de los intereses, preferencias y habilidades laborales de la persona, puesto que será fundamental para realizar un ajuste razonable entre las demandas del mercado laboral y el plan de empleo que, entre otros, incluirá el perfil profesional, plan de búsqueda, formación y las necesidades de apoyo de la persona (Plena Inclusión, 2018). El hecho de conocer estos intereses, preferencias y habilidades contribuirá, posteriormente, a identificar, acceder y mantener empleos significativos para la persona (Persch et al., 2015).

Tal como se muestra en la Tabla 5 , a través de dos subfases, esta segunda fase pretende, por un lado, recabar o actualizar la información disponible del perfil profesional de la persona y, por otro lado, elaborar el plan de empleo. Un primer momento consiste en revisar y actualizar el perfil profesional detallado de la persona, que incluya sus circunstancias personales y sociales, la formación y experiencia, competencias para la búsqueda de empleo y las competencias técnico-profesionales, así como los intereses y preferencias laborales. Basándonos en EUSE (2010) el perfil profesional se entiende como una herramienta que permite recoger información detallada sobre las habilidades, motivaciones y conocimientos de la persona, dirigida a conseguir el mejor ajuste posible entre la persona y las oportunidades de empleo y orientada a facilitar el proceso de conseguir y mantener un empleo. A su vez, y al tratarse de un proceso de recogida de información y contraste, para la actualización de este perfil profesional será necesario el trabajo conjunto del profesional técnico de acompañamiento y la persona trabajadora de inserción.

En la medida que las empresas de inserción disponen de sus propias herramientas, la idea es partir de ellas para complementarlas con algunos componentes. Por ello, la primera fuente de información sobre la persona que utilizaremos será la Escala de Factores de Empleabilidad (EFE). Los resultados de la escala incluyen la situación de la persona con relación a las distintas dimensiones de factores individuales de empleabilidad (circunstancias personales y sociales, formación básica y profesional, búsqueda de empleo, desempeño social y laboral), información cualitativa sobre las necesidades y apoyos en cada una de ellas, y las competencias técnicas de la persona en función de su ámbito ocupacional. Esta primera información se complementará con los intereses y preferencias laborales de la persona, tanto referidos a los tipos de puestos como a sus características y condiciones. En aquellos casos en los que ya se hayan desarrollado procesos previos de búsqueda de empleo, será interesante analizar con la persona lo que ha funcionado y no ha funcionado en dichos procesos, así como chequear el uso de las técnicas de búsqueda de empleo.

Tras la información recogida y registrada en el perfil profesional se diseña el plan de empleo, que se entiende como la herramienta que especificará las actividades acordadas, las fechas y sus 
Tabla 6. Fase 2: evaluación del perfil profesional y plan de empleo

\begin{tabular}{|c|c|c|c|}
\hline Subfases & Objetivos & Indicaciones estrategias & Herramientas \\
\hline Perfil profesional & $\begin{array}{l}\text { - Actualizar el perfil profesional. } \\
\text { - Actualizar la información de los } \\
\text { intereses y preferencias laborales, } \\
\text { así como otras características y } \\
\text { condicionantes. } \\
\text { - Evaluar con profundidad las } \\
\text { estrategias que utiliza en búsqueda } \\
\text { de empleo. }\end{array}$ & $\begin{array}{l}\text { - Aplicar la Escala de Factores de } \\
\text { Empleabilidad incorporando los aspectos } \\
\text { cualitativos y las competencias técnicas. } \\
\text { - Contrastar los resultados disponibles con } \\
\text { la persona. } \\
\text { - Concretar la información cualitativa sobre } \\
\text { necesidades y apoyos y la dimensión de } \\
\text { competencias técnicas en función de su } \\
\text { ámbito ocupacional. } \\
\text { - Dialogar sobre expectativas laborales, } \\
\text { preferencias o intereses con la persona. } \\
\text { - Revisar información sobre sus intereses con } \\
\text { relación a los puestos de trabajo o tipos de } \\
\text { ocupación. } \\
\text { - Recoger sus características y } \\
\text { condicionantes con relación al empleo. } \\
\text { - Analizar las experiencias de búsqueda } \\
\text { de empleo o de empleo para identificar } \\
\text { fortalezas y debilidades. }\end{array}$ & $\begin{array}{l}\text { - Escala de Factores } \\
\text { de Empleabilidad } \\
\text { con parte cualitativa } \\
\text { y competencias } \\
\text { técnicas. } \\
\text { - Ficha de intereses y } \\
\text { preferencias laborales. }\end{array}$ \\
\hline Plan de empleo & - Diseñar el plan de empleo. & $\begin{array}{l}\text { - Revisar la información recogida en el perfil } \\
\text { profesional. } \\
\text { - Establecer un encuentro para definir el plan } \\
\text { específico de la primera fase del proceso: la } \\
\text { búsqueda de empleo. } \\
\text { - Proponer acciones, tiempos y responsables } \\
\text { para dar inicio al proceso. } \\
\text { - Concretar el proceso de seguimiento. }\end{array}$ & $\begin{array}{l}\text { Plan de empleo y } \\
\text { seguimiento. }\end{array}$ \\
\hline
\end{tabular}

responsables. Será, en definitiva, la herramienta que vaya concretando los objetivos y las acciones que se vayan proponiendo en las distintas fases, detallando los tiempos y responsables. A su vez, esta herramienta permitirá hacer el seguimiento del proceso de acompañamiento a lo largo de las distintas fases. Por tanto, el plan de empleo se irá desarrollando en cada una de las fases, elaborando un plan específico para cada una de ellas y estableciendo unos tiempos de realización. Las fases identificadas son las siguientes:

- Búsqueda de oportunidades de empleo.

- Ajuste persona-puesto y apoyo a procesos de selección y contratación.

- Incorporación al puesto de trabajo (primeros quince días de empleo).

- Mantenimiento del empleo y desarrollo sociolaboral.

\subsection{Búsqueda de empleo y análisis de ofertas y puestos de trabajo}

El proceso de búsqueda de oportunidades laborales es un proceso compartido en el que tanto la persona en inserción como la técnica buscan oportunidades y ofertas de empleo. El objetivo de esta fase es identificar aquellos puestos de trabajo que pueden ser desempeñados por la persona y que se ajustan a sus intereses, preferencias y circunstancias.

Aunque los elementos clave de la fase son los mismos, en función de las circunstancias de cada persona y de cada empresa el proceso puede desarrollarse de diferentes formas o con un orden diferente. El aspecto que va a condicionar tanto el desarrollo de esta fase como de las siguientes es el grado de intensidad con el que desarrollemos acciones de intermediación entre la persona y la empresa. El nivel de intervención vendrá determinado por las preferencias de la persona, aunque van a verse condicionadas por las características de las empresas y su grado de colaboración.

Como se observa en la Tabla 7, la idea básica es que se trata de desarrollar un proceso en paralelo o conjunto en el que, por una parte, la persona desarrolla un proceso de búsqueda de empleo (búsqueda de ofertas, envío de currículum y cartas de presentación, activación de redes familiares y sociales, etc.) y, por otra parte, la persona técnica de acompañamiento también identifica algunas ofertas y hace un trabajo específico de prospección y de contacto con algunas de esas empresas de cara a ofrecer el apoyo del programa a la empresa, al tiempo que se identifican con más precisión los puestos de trabajo, sus requisitos y condiciones. Podemos decir que se trata de trabajar juntas en el proceso de búsqueda de empleo, sabiendo que tanto la persona técnica de acompañamiento como la persona trabajadora de inserción pueden desarrollar algunas acciones específicas, dependiendo de cada caso y enfatizando unas u otras en función de las necesidades y de las preferencias de las personas.

Un aspecto clave en esta fase que no es fácil de estandarizar se relaciona con las formas de presentación de la persona y de nuestro propio papel. A pesar de que las etiquetas pueden desempeñar un papel protector en algunas situaciones o facilitar el acceso a determinadas ayudas, en general tienden a estigmatizar a las personas. Por tanto, y en la medida en que está en juego el derecho de las personas a la 
confidencialidad, se trata de presentar a las personas y nuestro papel de formas culturalmente normativas, utilizando referentes cada vez más habituales en las empresas (tutores de prácticas, profesores de formación dual, formación en el puesto, etc.). En caso de ser conveniente dar algún tipo de información de carácter personal, es deseable que sea la propia persona la que lo haga y, en cualquier caso, siempre debe ser con su consentimiento y control. Relacionada con este tema aparece otra cuestión que hay que tener permanentemente en cuenta y que hace referencia al equilibrio entre la autonomía de la persona y la intensidad del apoyo que se le presta, evitando caer en cierto paternalismo.

Por último, disponer de una buena definición del puesto de trabajo es un aspecto de gran interés por cuanto nos facilita tanto conocer el contexto de la empresa como disponer de información relevante para valorar el grado de ajuste entre la persona y el puesto y, en consecuencia, diseñar los apoyos que la persona puede necesitar.

\subsection{Valoración grado de ajuste persona-puesto y apoyo en la selección y contratación}

Esta fase toma como referencia algunas de las actividades desarrolladas en las fases previas. Por una parte disponemos del perfil laboral de la persona y por otra disponemos de ofertas de empleo y, si es posible, de un análisis del puesto de trabajo. Aunque en esta guía la definimos como una fase, el análisis del grado de adecuación entre el perfil de la persona y del puesto es una actividad continua en el proceso de búsqueda de empleo que se puede desarrollar en diferentes momentos y de manera más o menos sistemática dependiendo de las circunstancias concretas.

Tabla 7. Fase 3: búsqueda de empleo y análisis de ofertas y puestos de trabajo

\begin{tabular}{|c|c|c|c|}
\hline Subfases & Objetivos & Indicaciones estrategias & Herramientas \\
\hline $\begin{array}{l}\text { Búsqueda de } \\
\text { empleo por } \\
\text { parte de la } \\
\text { persona en } \\
\text { inserción }\end{array}$ & $\begin{array}{l}\text { - Buscar e identificar } \\
\text { ofertas y } \\
\text { oportunidades de } \\
\text { empleo. }\end{array}$ & $\begin{array}{l}\text { - Asegurarse que la persona utiliza de manera eficaz las técnicas de } \\
\text { búsqueda de empleo. } \\
\text { - Identificar aspectos en los que la persona puede requerir de un apoyo } \\
\text { (búsqueda de ofertas, envío de currículum y cartas de presentación, } \\
\text { activación de redes familiares y sociales, etc.). } \\
\text { - Seguir los pasos de un proceso de búsqueda de empleo apoyando a la } \\
\text { persona en función de sus necesidades y preferencias: } \\
\text { - Identificar preferencias de empleo. } \\
\text { - Activar las redes de apoyo. } \\
\text { - Investigar posibles oportunidades. } \\
\text { - Planificar acciones de búsqueda (plan de empleo). } \\
\text { - Desarrollo de acciones: analizar ofertas y requisitos, responder } \\
\text { a ofertas, cartas, enviar currículum, preparación de procesos de } \\
\text { selección, etc. } \\
\text { - Hacer contrastes entre el perfil profesional y los requisitos del } \\
\text { puesto. }\end{array}$ & $\begin{array}{l}\text { Agenda de búsqueda } \\
\text { activa de empleo }\end{array}$ \\
\hline $\begin{array}{l}\text { Prospección } \\
\text { por parte de } \\
\text { la persona } \\
\text { trabajadora }^{1}\end{array}$ & $\begin{array}{l}\text { - Complementar } \\
\text { cuando sea } \\
\text { necesario con } \\
\text { una prospección } \\
\text { específica. }\end{array}$ & $\begin{array}{l}\text { - Activar todos los canales y recursos de búsqueda (orientadores/as, } \\
\text { prospectores/as, etc., de la entidad o de Gizatea). } \\
\text { - Disponer de información actualizada de ayudas a la contratación } \\
\text { (Gizatea). } \\
\text { - Cuando se identifica una posible oportunidad o una oferta concreta, } \\
\text { establecer contacto con la empresa para conocer con profundidad } \\
\text { la oferta y las características de la empresa, presentar a la persona } \\
\text { candidata y el programa (que puede realizarse de forma conjunta o no, } \\
\text { según cada caso). } \\
\text { - Adoptar lenguajes y referencias del ámbito empresarial. } \\
\text { - Presentarse desde el valor económico y social de las empresas de } \\
\text { inserción. } \\
\text { - Presentarse desde referentes culturalmente normativos (tutor/a de } \\
\text { prácticas o formación dual, formación en el puesto, etc.). } \\
\text { pstablecer un acuerdo con la empresa (posibilidad de análisis de } \\
\text { puesto, posibles pasos a realizar...). }\end{array}$ & \\
\hline $\begin{array}{l}\text { Análisis de } \\
\text { puestos }\end{array}$ & $\begin{array}{l}\text { - Complementar } \\
\text { cuando sea } \\
\text { necesario la oferta } \\
\text { de empleo con un } \\
\text { análisis detallado } \\
\text { del puesto de } \\
\text { trabajo. }\end{array}$ & $\begin{array}{l}\text { - Estar familiarizada con los perfiles profesionales relacionados con las } \\
\text { preferencias de las personas. } \\
\text { - Solicitar cuando sea pertinente conocer el puesto o puestos y ofrecer la } \\
\text { posibilidad de realizar un análisis de puestos. } \\
\text { - Es recomendable disponer de un análisis del puesto completo, ya que } \\
\text { nos va a permitir no solo tomar decisiones acerca de su idoneidad, } \\
\text { sino también identificar adaptaciones del puesto y posibles apoyos a } \\
\text { prestar. } \\
\text { - Analizar y describir el puesto a través de diferentes procedimientos } \\
\text { (observación directa, observación participante y/o entrevista). } \\
\text { - Conocer el perfil profesional de la persona nos puede ayudar a } \\
\text { identificar elementos clave a observar (por ejemplo, tareas, clima, } \\
\text { cultura, condiciones laborales, etc.). }\end{array}$ & $\begin{array}{l}\text { Ficha de oferta de } \\
\text { empleo y seguimiento. }\end{array}$ \\
\hline
\end{tabular}

${ }^{1}$ Aunque presentamos de forma diferenciada las actividades que realiza la persona trabajadora de inserción y la profesional técnica de acompañamiento, es un proceso compartido y bajo control de la persona, que es siempre informada de los pasos que da la profesional y con su consentimiento. 
El ajuste o grado de adecuación entre el perfil de la persona y las características del puesto de trabajo ha sido identificado como uno de los factores de satisfacción laboral, inclusión y pertenencia (Lysaght et al., 2017) y como un elemento clave en el mantenimiento del empleo, además de tener un impacto positivo en otras variables como rotación, compromiso o autoeficacia (Nützi et al., 2017). La propia idea de encaje o ajuste persona-puesto es congruente con nuestra visión de empleabilidad en la medida en que remite al ajuste dinámico entre las características de la persona y del puesto y que, en consecuencia, permite el desarrollo de adaptaciones o modificaciones tanto en la persona como en el entorno laboral. En este sentido, el desempeño laboral exitoso es producto de la interacción entre las circunstancias y capacidades de la persona y las exigencias y apoyos presentes en los lugares de trabajo.

El encaje laboral ha sido abordado desde diferentes perspectivas (Nützi et al., 2017) tanto desde puntos de vista de la psicología industrial y organizacional como de la orientación profesional o los programas de inserción laboral.

El encaje o ajuste laboral se define como el “emparejamiento entre los requisitos de la oferta de trabajo y las preferencias y capacidades de la persona" (Programa Incorpora, 2016: 37). Una definición más amplia (Persch et al., 2015: 271) hace referencia al "proceso de colaboración y de toma de decisiones basado en datos [...] para determinar la mejor adecuación entre las capacidades y preferencias de un individuo y las demandas ambientales y ocupacionales del puesto de trabajo". Como se apunta en esta definición, algunos de los elementos clave se relacionan con la complejidad de este proceso de emparejamiento y, en consecuencia, con la necesidad de utilizar fuentes diversas en el marco colaborativo y centrado en la persona, con la utilización de evidencias en un proceso sistemático.
Como se muestra en la Tabla 8, esta fase toma como referencia la información recogida, tanto con relación a la persona - perfil profesional- como del análisis del puesto de trabajo. El proceso de valoración de la adecuación entre el perfil de la persona y el puesto es un proceso que se puede desarrollar a diferentes niveles de profundidad. Un nivel básico supone hacer un contraste entre los requerimientos del puesto (habituales en las ofertas de empleo) con el grado en el que la persona posee dichos requisitos. También pueden desarrollarse procesos de evaluación más específicos si detallamos las tareas implicadas en los puestos de trabajo o de carácter más amplio si nos orientamos al ajuste entre la persona y la organización y no sólo un puesto de trabajo.

Es relevante que antes de presentar una candidatura se haya revisado el encaje entre la oferta de empleo y las preferencias y competencias de la persona.

\subsection{Incorporación, adaptación a la empresa y aprendizaje del puesto}

Esta fase (Tabla 9), se corresponde con la incorporación a la empresa. El aspecto clave es garantizar que la persona puede desenvolverse adecuadamente en sus primeros días en la empresa al mismo tiempo que se activan aquellos apoyos naturales ${ }^{2}$ que se pueden encontrar en el puesto de trabajo. Hay que tener en cuenta que los apoyos a prestar a la persona pueden variar considerablemente de una situación a otra y pueden incluir desde un apoyo directo en el acceso, adaptación y aprendizaje en el puesto de trabajo, hasta un apoyo indirecto a través de tutorías. Tanto las preferencias de la persona y la empresa como el grado de ajuste persona-puesto son las variables que van a determinar el tipo y la intensidad de los apoyos que se prestan. Es importante tener presente que, a pesar de que la persona tiene experiencia en la empresa de inserción, a veces, hay bastante

Tabla 8. Fase 4: valoración del grado de ajuste persona-puesto y apoyo en la selección y contratación

\begin{tabular}{|c|c|c|c|}
\hline Subfases & Objetivos & Indicaciones estrategias & Herramientas \\
\hline $\begin{array}{l}\text { Adecuación } \\
\text { persona-puesto }\end{array}$ & $\begin{array}{l}\text { - Analizar el } \\
\text { grado de ajuste } \\
\text { entre persona y } \\
\text { puesto. }\end{array}$ & $\begin{array}{l}\text { - El grado de sistematicidad de este proceso va a estar influido por el tipo } \\
\text { de puestos de trabajo y la necesidad de apoyo de la persona. } \\
\text { - Hacer el análisis trasladando la información del perfil profesional y del } \\
\text { análisis del puesto. } \\
\text { - Valorar con la persona los resultados } \\
\text { - Identificar posibles apoyos o ajustes a realizar en función de los } \\
\text { resultados. }\end{array}$ & $\begin{array}{l}\text { Ficha de ajuste } \\
\text { laboral. }\end{array}$ \\
\hline $\begin{array}{l}\text { Apoyo a proceso } \\
\text { de selección y } \\
\text { contratación }\end{array}$ & $\begin{array}{l}\text { Desarrollar } \\
\text { procesos de } \\
\text { selección } \\
\text { exitosos. }\end{array}$ & $\begin{array}{l}\text { - Animar la participación en entrevistas de selección. } \\
\text { - Preparar y ensayar con frecuencia entrevistas de selección en diferentes } \\
\text { - Anmatos, con diferentes personas. } \\
\text { - Identificar y y preparación de los resultados de las entrevistas. } \\
\text { ocupacionales. }\end{array}$ & \\
\hline
\end{tabular}

${ }^{2}$ Los apoyos naturales son cualquier estrategia, recurso, relación o interacción proporcionada por personas, procedimientos, ins trumentos o equipamiento que se encuentran típicamente disponibles en el lugar de trabajo. Por ejemplo, el apoyo de un compañero/a en una tarea nueva, las indicaciones de un/a responsable o seguir un manual de instrucciones. 
distancia entre las exigencias de esta y las de la empresa ordinaria, tanto con relación a los ritmos y cargas de trabajo como con relación a las condiciones de trabajo (flexibilidad, etc.).

En cualquiera de estas situaciones, el aspecto común es el contacto regular con la persona, la disponibilidad en diferentes formatos (café, contacto telefónico, WhatsApp, tutoría, etc.), funcionando como "red social de apoyo" y estando atentas a identificar con rapidez si aparecen algunas dificultades, tanto en la empresa como en la situación general de la persona.

\subsection{Mantenimiento del empleo y desarrollo profesional}

Una vez superado el periodo de prueba, se trata de que la persona desempeñe el trabajo de forma satisfactoria para ella y para la empresa. En este sentido, se trata de realizar un seguimiento de ese desempeño y de la identificación de algunas circunstancias tanto laborales como personales que lo pueden dificultar. Para ello, la tipología de apoyos puede ser diversa en función de la situación de la persona y la relación con la empresa, pero pueden incluir desde encuentros puntuales con la persona, hasta visitas a la empresa, entrevistas con el personal de la empresa, autoevaluación del desempeño, etc.

En cualquier caso, lo más relevante en esta fase, tal como se muestra en la Tabla 10, es la identificación, lo más tempranamente posible, de los apoyos que hay que prestar a la persona tanto dentro como fuera del puesto de trabajo. Para ello, se trata de mantener el contacto regular con la persona, funcionar como red de apoyo, estando disponible con la referencia de lo que la persona prefiere. Puede ser un contacto informal, una llamada de teléfono, una reunión más formal, etc.

Con relación a la empresa, se puede ofrecer la disponibilidad para realizar el seguimiento, contando con el acuerdo del trabajador o trabajadora. Sin embargo, es importante tener en cuenta que la necesidad de apoyos y seguimiento vaya disminuyendo con el tiempo, buscando el empoderamiento y el desarrollo laboral y profesional de la persona.

Por último, en la medida en que el empleo se vaya consolidando, es deseable identificar oportunidades de promoción o vías de mejora profesional que la persona quiera poner en marcha. Para ello, se pueden establecer algunos encuentros para valorar cómo está la persona, cuáles son sus expectativas y si es necesario poner en marcha nuevas acciones.

\subsection{Evaluación}

Tanto a lo largo del proceso como al finalizar el programa es necesario hacer una evaluación tanto del proceso como de los resultados obtenidos. Por una parte, a lo largo del proceso se irá recogiendo información a través de las herramientas propuestas,

Tabla 9. Fase 5: incorporación, adaptación a la empresa y aprendizaje del puesto

\begin{tabular}{|c|c|c|c|}
\hline Subfases & Objetivos & Indicaciones estrategias & Herramientas \\
\hline $\begin{array}{l}\text { Preparación } \\
\text { y orientación } \\
\text { primeros días }\end{array}$ & $\begin{array}{l}\text { - Facilitar la } \\
\text { adaptación al empleo } \\
\text { planificando la } \\
\text { acogida. }\end{array}$ & $\begin{array}{l}\text { Preparar el primer día de trabajo con la persona en inserción. } \\
\text { Preguntar si quiere ser acompañada/o, si se busca un apoyo } \\
\text { trabajador, encargado/a, alguien que desde dentro pueda } \\
\text { ayudarle en su presentación o que se encarga de la acogida, } \\
\text { podría ser su mentor/a (EUSE, 2010). }\end{array}$ & $\begin{array}{l}\text { - Plan de empleo y } \\
\text { seguimiento. }\end{array}$ \\
\hline $\begin{array}{l}\text { Adaptación y } \\
\text { aprendizaje del } \\
\text { puesto }\end{array}$ & $\begin{array}{l}\text { Planificar apoyos para } \\
\text { el desempeño del } \\
\text { puesto con éxito. }\end{array}$ & $\begin{array}{l}\text { - Primera Identificación de necesidades de apoyo. } \\
\text { Poner en marcha los apoyos necesarios bajo la dirección de } \\
\text { la persona, sabiendo que se recomienda que sean lo más } \\
\text { naturales y con la menor intensidad posible. } \\
\text { - Realizar procesos de formación en el puesto (cuando sea } \\
\text { necesario). } \\
\text { - Contacto regular con la persona (llamada, reunión, etc.) y con la } \\
\text { persona de referencia en la empresa. }\end{array}$ & $\begin{array}{l}\text { - Plan de Empleo y } \\
\text { seguimiento. } \\
\text { - Puede ser necesario } \\
\text { elaborar herramientas } \\
\text { específicas para } \\
\text { el aprendizaje o } \\
\text { seguimiento del } \\
\text { desempeño. }\end{array}$ \\
\hline
\end{tabular}

Tabla 10. Fase 6: mantenimiento del empleo y desarrollo profesional

\begin{tabular}{|c|c|c|c|}
\hline Subfases & Objetivos & Indicaciones estrategias & Herramientas \\
\hline $\begin{array}{l}\text { Mantenimiento } \\
\text { del puesto }\end{array}$ & $\begin{array}{l}\text { - Asegurar que la } \\
\text { incorporación es } \\
\text { exitosa. } \\
\text { - Detectar dificultades } \\
\text { dentro y fuera del } \\
\text { entorno laboral } \\
\text { y apoyar para la } \\
\text { resolución. }\end{array}$ & $\begin{array}{l}\text { - Mantener contacto y disponibilidad para el seguimiento. } \\
\text { - Prestar atención al estado emocional. } \\
\text { - Acompañar a la persona en la identificación de dificultades y en la } \\
\text { búsqueda de estrategias para resolverlas. } \\
\text { - Adecuación de los apoyos en el tiempo en función de necesidades } \\
\text { que puedan surgir en el puesto (cambios de tareas, nuevos } \\
\text { aprendizajes, más responsabilidades, etc.). } \\
\text { - Prestar atención a dos factores que se identifican como claves: las } \\
\text { relaciones sociales y los temas no laborales. }\end{array}$ & $\begin{array}{l}\text { - Plan de empleo y } \\
\text { seguimiento. }\end{array}$ \\
\hline $\begin{array}{l}\text { Promoción } \\
\text { y mejora } \\
\text { profesional }\end{array}$ & $\begin{array}{l}\text { Establecer un plan } \\
\text { de futuro para la } \\
\text { promoción y mejora } \\
\text { profesional y laboral. }\end{array}$ & $\begin{array}{l}\text { - Identificación de intereses laborales o/y formativos. } \\
\text { - Acordar un plan de acción para prospección, búsqueda de ofertas } \\
\text { laborales de interés, o planes formativos para mejora de necesidades } \\
\text { para el ajuste. } \\
\text { - Contacto regular con la persona en diferentes formatos. }\end{array}$ & \\
\hline
\end{tabular}


así como de la percepción de los diferentes agentes implicados. De manera específica será relevante recoger información sobre la propuesta metodológica que nos permita tomar decisiones de cambio 0 modificación de algunos de sus apartados con un especial énfasis en la tipología e intensidad de los apoyos que se han prestado.

Con relación a los resultados del programa, además de utilizar la Escala de Factores de Empleabilidad para identificar si se han producido algunos cambios en términos de empleabilidad, se recogerán datos de los resultados en términos de las características del empleo que han conseguido las personas. También sería importante recoger información de la satisfacción de las personas participantes, los profesionales y las propias empresas.

\section{Herramientas de apoyo}

Para el desarrollo metodológico del programa y para su evaluación se han elaborado o adaptado un conjunto de herramientas. En la Tabla 11 se presentan, atendiendo a las fases en las que se utilizan y haciendo una breve descripción de cada una de ellas.

Es importante entender estas herramientas no como una sucesión de fichas que se completan en un determinado orden, sino como un "cuaderno", con idas y vueltas en las diferentes herramientas y que vamos utilizando de forma simultánea según vamos disponiendo de información y vamos avanzando en las diferentes fases.

Tabla 11. Descripción de las herramientas de soporte al proceso de apoyo

\begin{tabular}{|c|c|c|}
\hline Fases & Herramientas & Descripción \\
\hline \multirow{3}{*}{$\begin{array}{l}\text { Fase 1. Encuadre y } \\
\text { decisión sobre la } \\
\text { participación }\end{array}$} & $\begin{array}{l}\text { Hoja o folleto } \\
\text { Informativo }\end{array}$ & $\begin{array}{l}\text { Herramienta de apoyo para informar a la persona acerca del funcionamiento, los } \\
\text { compromisos que conlleva y los apoyos disponibles del programa. } \\
\text { Permite contrastar/negociar el encuadre del programa, clarificar expectativas y concretar } \\
\text { compromisos asumidos, a través de un proceso de diálogo. }\end{array}$ \\
\hline & $\begin{array}{l}\text { Documento de } \\
\text { participación y } \\
\text { confidencialidad }\end{array}$ & $\begin{array}{l}\text { Acuerdo o contrato acerca de lo que vamos a hacer y cómo lo vamos a hacer. } \\
\text { Permite a la persona tomar una decisión informada acerca de su participación o no en el } \\
\text { programa. }\end{array}$ \\
\hline & $\begin{array}{l}\text { Carpeta/ } \\
\text { cuaderno } \\
\text { personal }\end{array}$ & $\begin{array}{l}\text { Se trata de un soporte de almacenamiento que permite guardar los documentos y recoger } \\
\text { la información que se vaya generando durante el proceso de búsqueda y mantenimiento del } \\
\text { empleo. } \\
\text { Sirve para hacer el seguimiento y monitorizar el proceso. }\end{array}$ \\
\hline \multirow{3}{*}{$\begin{array}{l}\text { Fase } 2 . \\
\text { Evaluación del perfil } \\
\text { profesional y plan de } \\
\text { empleo }\end{array}$} & $\begin{array}{l}\text { Escala de Factores } \\
\text { de Empleabilidad } \\
\text { con parte } \\
\text { cualitativa y } \\
\text { competencias } \\
\text { técnicas }\end{array}$ & $\begin{array}{l}\text { Mide el nivel de empleabilidad de las personas, a través de la valoración de } 144 \text { ítems } \\
\text { agrupados en siete dimensiones (circunstancias personales y sociales, formación básica, } \\
\text { formación profesional, experiencia profesional, búsqueda de empleo, desempeño social } \\
\text { en el trabajo y desempeño laboral). Se complementa con la valoración de las competencias } \\
\text { técnicas y una parte cualitativa que facilita la identificación de necesidades y apoyos. } \\
\text { Permite disponer de la información básica del perfil profesional de una forma sistemática } \\
\text { y sirve de referencia para diseñar planes y apoyos para las personas. Asimismo, permite } \\
\text { identificar cambios en la situación de las personas. }\end{array}$ \\
\hline & $\begin{array}{l}\text { Ficha de intereses } \\
\text { y preferencias } \\
\text { laborales }\end{array}$ & $\begin{array}{l}\text { Su objetivo es identificar y priorizar por grado de importancia las preferencias laborales y } \\
\text { las exclusiones en cada uno de los factores analizados, para poder focalizar la búsqueda y } \\
\text { selección y ajuste de las diferentes ofertas laborales. }\end{array}$ \\
\hline & $\begin{array}{l}\text { Plan de empleo y } \\
\text { seguimiento }^{3}\end{array}$ & $\begin{array}{l}\text { Herramienta compartida a través de la cual se fijan los acuerdos y compromisos que se } \\
\text { adoptan en el proceso de búsqueda y mantenimiento del empleo. } \\
\text { Permite realizar el seguimiento de todo el proceso, donde se irán registrando las acciones y } \\
\text { sus incidencias. } \\
\text { Es una oportunidad para los y las profesionales, pero también para las personas trabajadoras } \\
\text { en inserción en la medida que les permite hacerse cargo de su situación, valorarla, ser } \\
\text { propositivas y negociar el acompañamiento que necesitan. }\end{array}$ \\
\hline \multirow[b]{2}{*}{$\begin{array}{l}\text { Fase 3. Búsqueda de } \\
\text { empleo y análisis de } \\
\text { ofertas y puestos de } \\
\text { trabajo }\end{array}$} & $\begin{array}{l}\text { Agenda de } \\
\text { búsqueda activa } \\
\text { de empleo }\end{array}$ & $\begin{array}{l}\text { Es un registro de las actividades de búsqueda realizadas por la persona trabajadora en el } \\
\text { proceso de búsqueda de empleo. } \\
\text { Su objetivo es disponer de información del estado de los procesos de búsqueda y del } \\
\text { resultado para hacer un seguimiento y, en su caso, realizar mejoras. }\end{array}$ \\
\hline & $\begin{array}{l}\text { Ficha de } \\
\text { descripción del } \\
\text { puesto de trabajo } \\
\text { y seguimiento }\end{array}$ & $\begin{array}{l}\text { Se utiliza cuando hay intermediación con la empresa. Sirve para valorar el grado en el que el } \\
\text { puesto de trabajo se ajusta a las preferencias y características de la persona, para identificar } \\
\text { y diseñar los apoyos que la persona puede precisar, y para llevar a cabo el seguimiento de la } \\
\text { oferta y valorar el resultado de esta. } \\
\text { Es una adaptación de la ficha de Lanbide "Solicitud de oferta”, a la que se le ha añadido } \\
\text { dos apartados, uno para valorar el grado de colaboración de la empresa y otro para hacer el } \\
\text { seguimiento y valoración de la oferta. } \\
\text { Es una herramienta dinámica, que se puede ir cumplimentando por uno/a o varios/as } \\
\text { profesionales, a medida que se va desarrollando el proceso. }\end{array}$ \\
\hline $\begin{array}{l}\text { Fase } 4 \text {. Valoración } \\
\text { del grado de ajuste } \\
\text { persona-puesto y } \\
\text { apoyo en la selección y } \\
\text { contratación }\end{array}$ & $\begin{array}{l}\text { Ficha de ajuste } \\
\text { laboral }\end{array}$ & $\begin{array}{l}\text { El objetivo de esta herramienta es valorar el grado de ajuste entre el perfil profesional de la } \\
\text { persona y el perfil del puesto de trabajo. } \\
\text { Proporciona información útil tanto para seleccionar si un puesto de trabajo se adecúa a las } \\
\text { preferencias y competencias de la persona, como para identificar los apoyos necesarios } \\
\text { cuando hay una distancia entre uno y otro. }\end{array}$ \\
\hline
\end{tabular}

${ }^{3}$ El plan de empleo y seguimiento es una herramienta que se utiliza durante todo el proceso de acompañamiento y está vinculado a la fase 5, de incorporación, adaptación a la empresa y aprendizaje del puesto, y a la fase 6, de mantenimiento del empleo y desarrollo profesional. 


\section{Conclusiones}

En estos momentos el programa se está implementando, en clave de investigación-acción, con veinticuatro personas de trece empresas de inserción que reciben apoyo durante doce meses. La incorporación al programa está siendo progresiva entre abril y septiembre de 2019 según las personas van finalizando sus itinerarios en las empresas de inserción. Esperamos disponer de los resultados del programa en diciembre de 2020.

De cara a la evaluación del programa se ha diseñado un sistema de seguimiento y evaluación que incorpora la perspectiva de todas las personas participantes y que incluye tanto una recogida sistemática de información del proceso y resultados como el desarrollo de procesos de reflexión, contraste y análisis de la práctica. Además del uso de herramientas específicas de evaluación (registro de acciones del personal técnico, resultados de empleo y encuestas de satisfacción), se está desarrollando un seminario de profesionales, grupos focales con las personas participantes del programa y se ha configurado un equipo de contraste con el objetivo de tener una visión global del programa y coordinar su puesta en práctica que incluye las diferentes perspectivas del programa: personas participantes, profesionales, investigadoras y responsables del proyecto. 
AAIDD (2011): Discapacidad intelectual: definición, clasificación y sistemas de apoyo. Madrid, Alianza.

ÁLVAREZ DE EULATE, L. (2017): “Empresas de inserción vascas: una herramienta eficaz y eficiente para la inclusión sociolaboral”, Zerbitzuan, 64, 189201, 〈https://doi.org/10.5569/1134-7147.64.13〉.

ASKUNZE, C. (2016): “Empresas de inserción en la economía social. Herramientas para la inclusión sociolaboral”, Revista Jurídica, 29, 1-32, shttps://www.economiasolidaria.org/sites/ default/files/empresas_insercion_askunze. pdf>.

BLOOM, D. (2010): Transitional Jobs: Background, Program Models, and Evaluation Evidence, New York, 〈https://www.acf.hhs.gov/sites/default/files/ opre/tj_09_paper_embed.pdf $\rangle$.

BLUMENBERG, E. (2002): "On the Way to Work: Welfare Participants and Barriers to Employment", Economic Developmental Quartely, 16 (4), 314-325, <https://doi. org/10.1177/089124202237196>.

DANZIGER, S.; CORCORAN, M.; DANZIGER et al. (2002): Barriers to the Employment of Welfare Recipients, PSC Research Report No. 02-508, Ann Arbor, 〈https://www.psc.isr.umich.edu/ pubs/abs/1337>.

DE GRIP, A.; VAN LOO, J. y SANDERS, J. (2004): “The Industry Employability Index: Taking account of supply and demand characteristics", International Labour Review, 143 (3), 211-233.

DOWLER, D.L. y WALLS, R.T. (2014): “A Review of Supported Employment Services for People with Disabilities: Competitive Employment, Earnings and Service Costs", Journal of Rehabilitation, $80(1), 11-21$.

EUROPEAN UNION SUPPORTED EMPLOYMENT (2010): Caja de Herramientas para la diversidad de la Unión Europea de Empleo con Apoyo, European Union Supported Employment Lifelong Learning Programme, «http://euse.org/content/toolkit/
EUSE\%20Toolkit\%2ofor\%20Diversity\%20 Spanish.pdf〉.

FAEDEI y AERESS (2014): El acompañamiento en las empresas de inserción, Madrid, 〈http://www. faedei.org/images/docs/documento49.pdf〉.

FANTOVA, F. (2009): “Nota sobre acompañamiento social y autonomía personal", Políticas Sociales en Europa, 25, 167-175.

FERNÁNDEZ, A.; GALARRETA, J. y MARTÍNEZ, N. (2007): Manual de Acompañamiento en las Empresas de Inserción: Proceso y herramientas, Bilbao, Gizatea.

FERNÁNDEZ, R.; IMMERVOLL, H.; PACÍFICO, D. y THÉVENOT, C. (2016): "Faces of Joblessness: Characterising Employment Barriers to Inform Policy", OECD Social, Employment and Migration Working Papers, 192, París, 〈https://doi. org/10.1787/5jlwvz47xptj-en〉.

FORRIER, A. y SELS, L. (2003): “The concept employability: a complex mosaic", International Journal Human Resources Development and Management, 3 (2), 102-124, 〈https://doi.org/10.1504/ IJHRDM.2003.002414>.

FREDERICK, D.E. y VANDERWEELE, T.J. (2019): “Supported employment: Meta-analysis and review of randomized controlled trials of individual placement and support", PLOS ONE, 14 (2), 〈https://doi.org/10.1371/journal. pone.0212208>.

GALLASTEGI, A. y MARTínEZ, N. (2011): La Mejora de los Procesos de Acompañamiento en las Empresas de Inserción, Bilbao, Gizatea.

GIZATEA (2018): Las Empresas de Inserción en el País Vasco. Memoria Social 2017, Bilbao, Gizatea.

HILARIÓN, P. y KOATZ, D. (2012): Guía para la integración laboral de personas con trastorno mental, la Caixa, Barcelona, 〈https://www. incorporasaludmental.org/images/doc/D CAS_INI+ENT+EMP_DOCU_GUIA_0047_Guia_ Integ_Laboral.pdf〉. 
JORDÁN DE URRÍES, F.B. (2005): Estándares Europeos de Calidad para los Servicios de Empleo con Apoyo. Instrumento de evaluación, Salamanca, 〈http://sid.usal.es/idocs/F8/FD010984/ estandares_evaluacion.pdf $\rangle$.

LÁZARO, E. y MARTÍNEZ POLO, M.Á. (2013): “El tránsito al empleo de las personas más desfavorecidas a través de las empresas de inserción", Cuadernos de Trabajo Social, 26 (2), 467-478.

LEE, S.J.; AMIRAM, A. y VINOKUR, D. (2007): “Work Barriers in the Context of Pathways to the Employment of Welfare-to-Work Clients", American Journal on Community Psychology, 40, 301-312, 〈https://doi.org/10.1007/s10464-007-9144-x〉.

LLINARES, L.I. y CÓRDOBA, A.I. (2012): “La medida de la empleabilidad en las empresas de inserción en el País Vasco: de la exclusión a la inserción sociolaboral", Zerbitzuan, 51, 83-94, <https:// doi.org/10.5569/1134-7147/51.05>.

LYSAGHT, R.; PETNER-ARREY, J.; HOWELL-MONETA, A. y COBIGO, V. (2017): "Inclusion Through Work and Productivity for Persons with Intellectual and Developmental Disabilities", Journal of Applied Research in Intellectual Disabilities, 20, 922935, 〈https://doi.org/10.1111/jar.12284〉.

MARTÍNEZ-RUEDA, N. y FERNÁNDEZ, A. (2007): "La necesaria actualización de los centros ocupacionales", Zerbitzuan, 42, 45-56.

MARTÍNEZ-RUEDA, N.; GALARRETA, J. Y AROSTEGUI, I. (2018): "Factores organizacionales que inciden en la mejora de la empleabilidad de las Empresas de Inserción", CIRIEC-España, Revista de Economía Pública, Social y Cooperativa, 94, 123-154, 〈https://doi.org/10.7203/CIRIEC-E.94.12697〉.

MARTÍNEZ-RUEDA, N. y GALARRETA LASA, J. (2019): El acompañamiento en las Empresas de Inserción. Avances en el modelo de Gizatea, Bilbao, Gizatea.

MARTÍNEZ-RUEDA; N.; GALARRETA LASA, J. y ARÓSTEGUI BARANDICA, I. (2018): “Empleabilidad y empresas de inserción: modelo de prestaciones y apoyos", Zerbitzuan, 67, 79-93, 〈https://doi. org/10.5569/1134-7147.67.06>.

MARTÍNEZ MORALES, I.; BERNAD GARCÍA, J.C. y NAVAS SAURÍN, A. (2012): "Las empresas de inserción social en un contexto de cambios sociolaborales. Un análisis crítico de su regulación desde la normativa vasca y estatal”, Zerbitzuan, 51, 67-81, 〈https://doi. org/10.5569/1134-7147/51.04>.

MCQUAID, R.W. y LINDSAY, C. (2005): “The Concept of Employability”, Urban Studies, 42 (2), 197-219, 〈https://doi.org/10.1080/004209804200031 6100>.

MODINI, M.; TAN, L.; BRICHMANN, B.; WANG, M.; KILLACKEY, E.; GLOZIER, N. y HARVEY, S.B. (2016): "Supported employment for people with severe mental illness: systematic review and meta-analysis of the international evidence", The British Journal of Psychiatry, (209), 14-22, 〈https://doi.org/10.1192/bjp.bp.115.165092〉.

NATIONAL CENTER ON WORKFORCE AND DISABILITY/ ADULT (2005): Customized Employment: Practical Solutions for Employment Success, 〈http://digitalcommons.ilr.cornell.edu/ gladnetcollect/349>.
NATIONAL CENTER ON WORKFORCE AND DISABILITY/ADULT (2006): Customized employment, I y II, 〈http:// www.onestops.info/article.php\%3Farticle id $=419 . \mathrm{html}$.

NGA, A. y CHAN, W. (2015): “Social support for improved work integration Perspectives from Canadian social purpose enterprises", Social Enterprise Journal, 11(1), 47-68, https://doi.org/10.1108/ SEJ-07-2014-0033〉.

NÜTZI, M.; TREZZINI, B.; MEDICI, L. y SCHWEGLER, U. (2017): "Job matching: An interdisciplinary scoping study with implications for vocational rehabilitation counseling", Rehabilitation Psychology, 62 (1), 45-68, <https://doi. org/10.1037/repoooo119>.

OMS (2001): Clasificación Internacional del Funcionamiento, de la Discapacidad y de la Salud Madrid, IMSERSO.

PÉREZ ERANSUS, B. (2004): “El acompañamiento social como herramienta de lucha contra la exclusión", Documentación Social, (135), 89-107.

PERSCH, A.C.; CLEARY, D.S.; RUTKOWSKI, S.; MALONE, H.I.; DARRAGH, A.R. y CASE-SMITH, J.D. (2015): "Current practices in job matching: A Project SEARCH perspective on transition", Journal of Vocational Rehabilitation, 43, 259-273, 〈https://doi.org/10.3233/JVR-150774〉.

PLANELLA, J. (2008): “Educación social , acompañamiento y vulnerabilidad : hacia una antropología de la convivencia", Revista Iberoamericana de Educación, 46 (5), 1-14.

PLENA INCLUSIÓN (2018): Empleo Personalizado. Una oportunidad para crear situaciones únicas, Madrid, Plena Inclusión, 〈http://www. plenainclusion.org/sites/default/files/cbp_ empleo_personalizadoweb.pdf $>$.

PROGRAMA INCORPORA E INSTITUTO UNIVERSITARIO AVEDIS DONABEDIAN - UAB (2016): Indicadores para la mejora de la calidad del Programa Incorpora de integración sociolaboral, 〈https://www. incorpora.org/documents/20181/121139/ Indicadores+calidad.pdf $\rangle$.

PROGRAMA INCORPORA DE LA CAIXA e INSTITUTO UNIVERSITARIO AVEDIS DONABEDIANUAB (2016): Elementos de calidad para promover la Integración Sociolaboral Guía de la metodología del Programa Incorpora, Barcelona, <https://www. incorpora.org/documents/20181/121139/ Guia+Metodologia+Incorpora.pdf〉.

SERRANO PASCUAL, A. (2000): "El concepto de empleabilidad en la estrategia europea de lucha contra el desempleo: Una perspectiva crítica", Revista del Ministerio de Trabajo e Inmigración, 21, 137-150.

SIIS CENTRO DE ESTUDIOS Y DOCUMENTACIÓN (2011): Activación y derecho a la inclusión en el marco de las políticas de empleo y de garantía de ingresos en la CAPV, SIIS Centro de Estudios y Documentación, 〈https://www.siis.net/ documentos/ficha/197806.pdfs.

WILLIAMS, S.; DODD, L.; STEELE, C. y RANDALL, R. (2015): “A systematic review of current understandings of employability", Journal of Education and Work, 29 (8), 877-901, <https://doi.org/10.1080/1363 9080.2015.1102210〉. 